\title{
Matside Medical Aid during Judo Competition in Japan
}

\author{
A. Ikumi ${ }^{1,2}$, N. Sakuyama ${ }^{2,3}$, N. Takatori ${ }^{2,4}$, T. Kamitani ${ }^{2,5}$, S. Miyazaki ${ }^{2,6}$, Y. Nimura ${ }^{2,7}$, \\ N. Maffulli8,9, N. G. Malliaropoulos 9,10, S. Nagahiro 2,11 \\ 1 Department of Orthopaedic Surgery, Faculty of Medicine, University of Tsukuba, Ibaraki, Japan \\ 2 All Japan Judo Federation Medical Committee, Tokyo, Japan \\ 3 Division of Colorectal Surgery, Tobu Chiiki hospital, Tokyo Metropolitan Health and Medical Treatment \\ Corporation, Tokyo, Japan \\ ${ }^{4}$ Department of Orthopaedic Surgery, Tokai University School of Medicine, Kanagawa, Japan \\ ${ }^{5}$ Department of Orthopaedics, Japan Community Healthcare Organization, Tokyo Shinjuku Medical Center, \\ Tokyo, Japan \\ - School of Physical Education, Tokai University, Kanagawa, Japan \\ 7 International Judo Federation Medical Commission, Tokyo, Japan \\ ${ }^{8}$ Department of Musculoskeletal Disorders, Faculty of Medicine, Surgery and Dentistry, University of Salerno, \\ Salerno, Italy \\ 9 Centre of Sports and Exercise Medicine, Queen Mary University of London, London, UK \\ ${ }^{10}$ Institute of Science and Technology in Medicine, Keele University School of Medicine, Stoke on Trent, England \\ ${ }^{11}$ Department of Neurosurgery, Tokushima University, Tokushima, Japan
}

\section{CORRESPONDING AUTHOR:}

\section{Akira Ikumi}

Department of Orthopaedic Surgery

Faculty of Medicine

University of Tsukuba

Ibaraki, Japan

1-1-1 Tennoudai Tsukuba

Ibaraki, 3058575 Japan

Phone: +81-0298533219

E-mail: ikumi@tsukuba-seikei.jp

DOI:

10.32098/mltj.04.2019.19

LEVEL OF EVIDENCE: 4

\section{SUMMARY}

Background. This study aimed to investigate the trend of injuries occurring during judo competition reported by matside healthcare professionals. Seventeen judo competitions were investigated.

Methods. Injury data (severity, location, type and emergency transportation to medical institution) were recorded on-site using a simple injury reporting form with sex, age and weight category. A total of 420 injuries were recorded.

Results. The overall injury incidence rate per 1,000 athlete-exposures $\left(\mathrm{IIR}_{\mathrm{AE}}\right)$ was 22.7. The occurrence of minor injuries was four times than that of major injuries, and most minor injuries were to the soft tissue (bleeding). Sprain was the most frequent major injury followed by concussion. The $\operatorname{IIR}_{\mathrm{AE}}$ of minor injury in males was almost twice as high as in females; the highest IIR ${ }_{\mathrm{AE}}$ of minor injuries were recorded in college and over-age category. In major injury, the $\mathrm{IIR}_{\mathrm{AE}}$ of middleweight was higher than other weight categories. The most common injury requiring emergency transportation was concussion. The frequencies and characteristics between minor and major injuries were different. The most common minor injury was bleeding, and major injury was sprain.

Conclusions. To properly respond to injured athletes during a bout, matside healthcare professionals need to undergo training and learn the knowledge of judo-related injuries.

\section{KEY WORDS}

atbletic injuries; epidemiology; judo; martial arts 


\section{BACKGROUND}

Judo is a martial art and combat sport originating from Japan, characterised by a combination of standing (throws and takedowns) and ground fighting (holding down, choking and joint locking). In judo competition, striking techniques are forbidden. The International Judo Federation (IJF) is the largest international sport judo organisation with an estimated 40 million practitioners in more than 200 member countries and is recognised by the International Olympic Committee (1). Judo became an Olympic sport for men at the Tokyo 1964 Olympic Games and for women at the Barcelona 1992 Olympic Games (2).

In sport judo competitions, the contestants are subdivided into categories based on sex, age and weight, and they are not required to wear personal protective gear.

As judo is a contact sport, it carries an inherent risk of injury to judokas. Therefore, efforts to prevent and mitigate the negative consequences of injury are warranted. A recent systematic review (3) summarised the findings from five prospective studies investigating the epidemiology of injuries during judo competitions. Most of these studies investigated elite adult judokas, and only one study included young judokas (4-8). The overall injury incidence rates per 1,000 athlete-exposures $\left(\mathrm{IIR}_{\mathrm{AE}}\right)$ range from 30.3 to 82.8, and the most commonly injured region was the upper limb, followed by the head and neck. Contusion was the most frequent type of injury. Most injuries occur during standing fighting (throwing or being thrown).

With regard to injury risk factors, the available evidence is either limited or conflicting. Although two studies have found that female judokas were at greater risk of injury than male judokas $(6,7)$, one study reported the opposite (5). Furthermore, one study found that young judokas had a higher $\operatorname{IIR}_{\mathrm{AE}}$ than their adult counterparts (8), and another study suggested that judokas in the middleweight classes had a lower $\mathrm{IIR}_{\mathrm{AE}}$ than lighter and heavier judokas (7). Moreover, rapid weight loss immediately prior to competition to meet weight class restrictions has been suggested as a possible injury risk factor (9). While the importance of an injury prevention programme has been advocated in past research studies (10-12), a consensus evidence-based injury prevention programme in judo has not yet been established. Improving the quality of matside (tatami) healthcare professionals and developing an injury prevention programme are critical for safety management at competitions. However, there are few reports, which investigate the details of injuries tended to, by tatami healthcare professionals during competition. Therefore, to clarify the trend of injuries during judo competition, the present study aimed to investigate injuries reported by tatami healthcare professionals during judo competitions in Japan.

\section{MATERIALS AND METHODS}

Injury and exposure data were collected from judokas competing in Japan during December 2015 to April 2018. The judokas competed within categories based on age groups (elementary school students: 6-12 years; middle school students: 13-15 years; high school students: 16-18 years; and college and over: $>18$ years) and sex and weight class (men: $\leq 60,66,73,81,90,100,>100 \mathrm{~kg}$ and openweight, women: $\leq 48,52,57,63,70,78,>78$ and openweight).

This study was conducted ethically according to international standards and as required by this journal (1) and approved by the Ethics Committee of All Japan Judo Federation, Tokyo, Japan (December 2015).

Exposure data were obtained from official competition records. All injuries were diagnosed by a medically licensed official competition tatami healthcare professional. Injury data were recorded on-site by tatami health care professionals using a simple injury reporting form immediately after each injury (figure 1).

The form included the following information: sex, weight class, details of injury (anatomical location, injury type, continue to bout and emergency transportation for medical institution).

An injury was defined as any physical complaint for which the referee and the judoka would seek assistance from a tatami health care professional during competition. Severity of injury in this study was divided into two groups based on whether the injured judoka can continue to bout (minor injury), or if the injured judoka cannot continue to bout (major injury). The unit of exposure was defined as a single judo bout.

Therefore, one athlete-exposure was defined as one judoka participating in one judo bout. Each bout was scheduled for 3-4 min. If opposing judokas achieved an identical score the end of the match, the contest is resolved by the Golden Score rule, which was a sudden death situation, where the clock is reset to match-time, and the first contestant to achieve any score wins.

There were four weight classes: lightweight $(<52 \mathrm{~kg}$ for women and $<66 \mathrm{~kg}$ for men); middleweight (52-70 kg for women and $66-90 \mathrm{~kg}$ for men); heavyweight (>70 kg for women and $>90 \mathrm{~kg}$ for men) and open-weight (no limitation of weight, different weight classes can compete against each other).

Statistical analysis was performed using the Statistical Package for Social Sciences for Mac 21.00 (SPSS Inc., USA). Pearson's chi-square test was used to compare injuries, which needed emergency transportation by sex, age and weight class. A value of $\mathrm{P}<0.05$ was considered to be statistically significant.

Muscles, Ligaments and Tendons Journal 2019;9 (4) 
Name of Competition;

Competition Date (mm/dd/yyyy); I 1

Competition Division; $\quad \square$ Elementary School Student

$\square$ Junior High School Student

$\square$ High School Student

$\square$ College and Over

Medical Personnel (Initial); ( $\square$ Medical Doctor / $\square$ Judo Therapist / $\square$ Other

--------Please fill out below contents when you coped with Judoka during the game-

Tatami Number;

Sex; $\square$ Male / $\square$ Female

Weight Category; $\square-60 \mathrm{~kg} / \square-66 \mathrm{~kg} / \square-73 \mathrm{~kg} / \square-81 \mathrm{~kg} / \square-90 \mathrm{~kg} / \square-100 \mathrm{~kg} / \square+100 \mathrm{~kg} / \square$ $\square-48 \mathrm{~kg} / \square-52 \mathrm{~kg} / \square-57 \mathrm{~kg} / \square-63 \mathrm{~kg} / \square-70 \mathrm{~kg} / \square-78 \mathrm{~kg} / \square+78 \mathrm{~kg} / \square \mathrm{o}$

Anatomical Injured Region;

$\square$ Head / $\square$ Face / $\square$ Eye / $\square$ Nose / $\square$ Mouth / $\square$ Ear / $\square$ Neck / $\square$ Clavicle / $\square$ Shoulder /

$\square$ Upper arm / $\square$ Elbow / $\square$ Forearm / $\square$ Wrist / $\square$ Hand / $\square$ Finger / $\square$ Nail / $\square$ Chest / $\square$ Abdor

$\square$ Back / $\square$ Hip / $\square$ Upper thigh / $\square$ Knee / $\square$ Lower thigh / $\square$ Ankle / $\square$ Foot / $\square$ Toe /

$\square$ Other

Type of Injury;

Bleeding ( $\square$ Rupture / $\square$ Abrasion / $\square$ Crack / $\square$ Laceration) / $\square$ Sprain / $\square$ Bruise / $\square$ Concuss $\square$ Dislocation / $\square$ Fracture / $\square$ Other

Emergency Transportation; $\quad \square$ Yes / $\square$ No

Other Comments;

Figure 1. Injury reporting form. 


\section{RESULTS}

In total, we analysed data from 18,470 athlete-exposures. A total of 420 injuries were recorded. The overall $\operatorname{IIR}_{\mathrm{AE}}$ was 22.7 (95\% CI, 20.4-38.5).

Table I shows an overview of the number of injuries and corresponding $\mathrm{IIR}_{\mathrm{AE}}$ categorised by injury severity, sex, age and weight category. Minor injuries comprised $78.8 \%$ of reports, and major injuries made up $21.2 \%$. There was no sex difference in $\mathrm{IIR}_{\mathrm{AE}}$ in major injury, but for minor injuries, the $\mathrm{IIR}_{\mathrm{AE}}$ of males was higher than females. With regard to age category, elementary school judokas had the highest $\mathrm{IIR}_{\mathrm{AE}}$ for major injury, whereas $\mathrm{IIR}_{\mathrm{AE}}$ of minor injury rose with increasing age category, with the highest in the college and over-age group. With regard to weight category, middleweights had at least double the $\mathrm{IIR}_{\mathrm{AE}}$ compared to any other weight category, while lightweights had the highest $\operatorname{IIR}_{\mathrm{AE}}$ in minor injury, followed by the middleweight category.

Table II shows an overview of the frequencies and proportions of injuries by injury type and anatomical location. The trends of injury type and anatomical location were different between minor and major injuries. Soft tissue injury (bleeding) was the most minor injury $(94.9 \%)$, and the most frequent anatomical location of minor injury was the head and neck (62.2\%) followed by upper limb (34.4\%). On the other hand, sprain was the most frequent major injury $(43.7 \%)$ followed by concussion $(14.6 \%)$, contu-

Table I. Number of injured judokas and IIR $\mathrm{AE}_{\mathrm{AE}}$ by severity, sex, age category and weight.

\begin{tabular}{|c|c|c|c|c|c|}
\hline & & \multicolumn{2}{|c|}{ Minor injury } & \multicolumn{2}{|c|}{ Major injury } \\
\hline & & Number & $\mathrm{IIR}_{\mathrm{AE}}$ & Number & $\mathrm{IIR}_{\mathrm{AE}}$ \\
\hline \multirow[t]{2}{*}{ Sex } & Male & 256 & 21.1 & 58 & 4.8 \\
\hline & Female & 75 & 11.9 & 31 & 4.9 \\
\hline \multirow{4}{*}{$\begin{array}{l}\text { Age category } \\
\text { (y) }\end{array}$} & Elementary school (6-12) & 5 & 7.9 & 6 & 9.5 \\
\hline & Middle school (13-15) & 35 & 11.4 & 14 & 4.6 \\
\hline & High school (16-18) & 146 & 16.3 & 19 & 2.1 \\
\hline & College and over $(>18)$ & 145 & 25.0 & 50 & 8.6 \\
\hline \multirow{4}{*}{$\begin{array}{l}\text { Weight } \\
\text { category }(\mathrm{kg})\end{array}$} & Lightweight (M:<66/F:<52) & 60 & 31.5 & 9 & 4.7 \\
\hline & Middleweight (M:73-90/F:57-70) & 83 & 29.0 & 27 & 9.4 \\
\hline & Heavyweight (M: >100/F:>78) & 33 & 17.3 & 7 & 3.7 \\
\hline & Open-weight (No limitation) & 155 & 13.1 & 46 & 3.9 \\
\hline Total & & 331 & 17.9 & 89 & 4.8 \\
\hline
\end{tabular}

Table II. Injuries by severity, type of injury and anatomical location.

\begin{tabular}{|c|c|c|c|c|c|}
\hline \multirow[b]{2}{*}{ Injury type } & \multirow[b]{2}{*}{ Concussion } & \multicolumn{2}{|c|}{$\begin{array}{c}\text { Minor injury } \\
(\mathrm{n}, \%)\end{array}$} & \multicolumn{2}{|c|}{$\begin{array}{c}\text { Major injury } \\
(\mathrm{n}, \%)\end{array}$} \\
\hline & & 0 & 0 & 13 & 14.6 \\
\hline & Contusion & 7 & 2.1 & 12 & 13.5 \\
\hline & Dislocation & 1 & 0.3 & 9 & 10.1 \\
\hline & Fracture & 0 & 0 & 11 & 12.4 \\
\hline & Soft tissue injury (Bleeding) & 314 & 94.9 & 2 & 2.2 \\
\hline & Sprain & 9 & 2.7 & 38 & 42.7 \\
\hline & Other & 0 & 0 & 4 & 4.5 \\
\hline \multirow[t]{5}{*}{ Anatomical location } & Head and Neck & 206 & 62.2 & 25 & 28.1 \\
\hline & Trunk & 5 & 1.5 & 5 & 5.6 \\
\hline & Upper Limb & 114 & 34.4 & 33 & 37.1 \\
\hline & Lower Limb & 6 & 1.8 & 24 & 27.0 \\
\hline & Other & 0 & 0 & 2 & 2.2 \\
\hline Total & & 331 & 100 & 89 & 100 \\
\hline
\end{tabular}


sion $(13.5 \%)$ and fracture $(12.4 \%)$. The most common anatomical location of major injury was upper limb (37.1\%) followed by head and neck $(28.1 \%)$.

Twenty-seven injuries needed emergency transportation to medical institution (14 males and 13 females). The frequency of injuries needing emergency transportation is 1.5 per 1,000 athletes-exposures. The greatest number of injuries, which needed emergency transportation, was in the openweight class (lightweight $=4$, middleweight $=7$, heavyweight $=2$ and open-weight $=14)$. The most common anatomical location, which needed emergency transportation, was head $(37.0 \%)$, followed by neck (14.8\%) and elbow (14.8\%). The most common type of injury that needed emergency transportation was concussion $(33.3 \%)$, followed by cervical sprain $(14.8 \%)$, elbow dislocation $(14.8 \%)$, clavicle fracture $(11.1 \%)$ and shoulder dislocation $(11.1 \%)$. There were no significant differences in sex $(\mathrm{P}=0.13)$, age $(\mathrm{P}=0.18)$ and weight category with regard to emergency transportation (table III, $\mathrm{P}=0.74$ ).

\section{DISCUSSION}

We investigated trends of injury occurring during judo competition treated by tatami healthcare professionals, and determined differences across age, weight class and sex. In addition, severity of injury was divided into two groups based on whether the injured judoka was able to continue the bout.

\section{Severity of injury}

Soft tissue injury (bleeding) especially of the face or finger was the most common reported minor injury in this study. Being thrown, grip fighting and contact with tatami are major injury mechanisms in judo competition $(3,14)$. Because bleeding is usually classified as a minor injury $(14,15)$, it does not hinder the continuation of the match. However, in this study there were two cases of bleeding (nasal bleeding and head laceration) classified as major injury because of the difficulty in stopping the bleeding. The bout cannot be restarted until the bleeding is completely stopped, as stipulated by the referee regulations of the IJF (16). Furthermore, if the bleeding injury at the same locations requires treatment three times in a single bout, the injured judoka is disqualified, and thus declared the loser. Therefore, tatami healthcare professionals are under great pressure to definitively stop bleeding as quickly as possible during a bout. Therefore, to properly execute safety competition management without hindering the progress of a bout, tatami healthcare professionals need to learn adequate techniques and strategies to stop bleeding, such as taping and using hemostatic agents as permitted in the rules.
Table III. Injuries needing emergency transportation.

\begin{tabular}{|c|c|c|}
\hline Category & n & *P value \\
\hline \multicolumn{3}{|l|}{ Sex } \\
\hline Male & 14 & \multirow{2}{*}{0.13} \\
\hline Female & 13 & \\
\hline \multicolumn{3}{|l|}{ Age category } \\
\hline Elementary school (6-12 y) & 1 & \multirow{4}{*}{0.18} \\
\hline Middle school (13-15 y) & 8 & \\
\hline High school (16-18 y) & 8 & \\
\hline College and over (>18 y) & 10 & \\
\hline \multicolumn{3}{|l|}{ Weight category } \\
\hline $\begin{array}{l}\text { Lightweight } \\
(\mathrm{M}:<66 \mathrm{~kg} / \mathrm{F}:<52 \mathrm{~kg})\end{array}$ & 4 & \multirow{4}{*}{0.74} \\
\hline $\begin{array}{l}\text { Middleweight } \\
(\mathrm{M}: 73-90 \mathrm{~kg} / \mathrm{F}: 57-70 \mathrm{~kg})\end{array}$ & 7 & \\
\hline $\begin{array}{l}\text { Heavyweight } \\
(\mathrm{M}:>100 \mathrm{~kg} \mathrm{~F}:>78 \mathrm{~kg})\end{array}$ & 2 & \\
\hline Open-weight (No limitation) & 14 & \\
\hline \multicolumn{3}{|l|}{ Anatomical Location } \\
\hline Head and Neck & 2 & \\
\hline Head & 8 & \\
\hline Neck & 2 & \\
\hline Clavicle & 3 & \\
\hline Shoulder & 3 & \\
\hline Elbow & 4 & \\
\hline Wrist & 1 & \\
\hline Abdomen & 1 & \\
\hline Hip & 1 & \\
\hline Upper thigh & 1 & \\
\hline Knee & 1 & \\
\hline \multicolumn{3}{|l|}{ Injury type } \\
\hline Concussion and Cervical sprain & 2 & \\
\hline Concussion & 7 & \\
\hline Bruise & 3 & \\
\hline Sprain & 3 & \\
\hline Fracture & 5 & \\
\hline Dislocation & 6 & \\
\hline \multirow[t]{2}{*}{ Other } & 1 & \\
\hline & *Pearson' & quare test \\
\hline
\end{tabular}

Sprain was most frequent type of major injury in this study, which is consistent with many previous studies $(3,8,17,18)$ also identifying sprains as the most common injury during judo competition. However, only a few cases of sprain injury necessitated emergency transportation to a medical insti- 
tution (only three cases in this study). Concussion was the second most frequent major injury in this study, and emergency transportation was necessary about $70 \%$ of concussion injured judokas. Kamitani et al. reported that catastrophic head injuries in judo generally results from being thrown. Furthermore, they elaborated that beginners with less than three years of experience, and young age $(<20$ years $)$ are at greater risk of catastrophic head injury because of immature ukemi technique. Differentiation between concussion and catastrophic head injury is difficult by physical examination only. Advanced care at a medical institution, including imaging is necessary for differential diagnosis of concussion and acute subdural haematoma. Nagahiro and Mizobuchi encouraged injured judokas to seek care at a medical institution as quickly as possible when concussion is suspected (20). Therefore, if concussion is suspected, the injured judoka should seek emergency transportation to hospital as soon as possible. In Japan, judo coaches are obliged to attend an annual safety instructor workshop, which includes instruction regarding head injury. Our finding of emergency transported head injuries (including concussion) appear to be related to the workshop for judo coaches. However, we did not focus on concussion injuries in this study. Future detailed investigation of concussion occurrence during competition is required to develop preventive measures for concussion.

Time loss for sport is frequently used to determine the functional severity of sports injuries (21), with longer duration defining greater injury severity (22). In judo, tears of the anterior cruciate ligament and prolapse of the intervertebral vertebral discs are reported as the most serious judo injuries resulting in the greatest time loss (21). Tatami healthcare professionals must also follow up with injured judokas and pay attention to injuries, which might decrease their performance following injury.

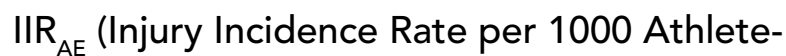 Exposures)}

In total, our overall $\operatorname{IIR}_{\mathrm{AE}}$ (22.7) was lower than previous studies investigating $\operatorname{IIR}_{\mathrm{AE}}$ during judo competition, which ranges from 35.6 to $81.6(6-8,10,14)$. Differences in survey sample, method, and definition of injury may explain these divergent results. Also, exclusion of the injuries not reported by tatami healthcare professionals might have affected the low $\mathrm{IIR}_{\mathrm{AE}}$ in this study. On the other hand, Gabbe et al. suggested that these differences may result from recall bias in questionnaire analysis and online survey (23). Additionally, injured athletes who did not consult a medical institution might be excluded in past studies, which used the data of medical record from hospital (11) and insurance database (24). Therefore, we believe the results of this study accu- rately reflect the frequency and trend of injuries occurring during judo competition.

In regard to sex differences, $\mathrm{IIR}_{\mathrm{AE}}$ of minor injury in men was twice as high as in women. In general, grip fighting and contact with tatami during a bout is greater in men due to their relatively greater power compared to women, which might explain this sex difference in minor injuries. On the other hand, we observed no sex difference in the $\operatorname{IIR}_{\mathrm{AE}}$ of major injuries. Previous studies also reported no sex difference in injury occurrence in judo (7).

Athletes under the age of 15 years are not permitted to attend IJF official (or sponsored) judo competitions, as stipulated by the Sport and Organisation Rules of the IJF (16). Age competition categories are classified as cadet: $15-17$ years (calendar year), junior: 15-20 years (calendar year) and senior: $>15$ years (calendar year). In Japan, competition categories are usually separated according to the type of school (elementary school, middle school, high school and college). Also, many judo competitions for elementary and middle school athletes are held throughout the year in Japan. For that reason, we classified competition category in accordance with Japanese categorisation in the present study.

In our study, minor injury $\operatorname{IIR}_{\mathrm{AE}}$ increased with age. This is likely a consequence of the increase in physical strength, which comes with body growth that increases the intensity of grip fighting and contact with tatami. In contrast, major injury $\mathrm{IIR}_{\mathrm{AE}}$ was higher in elementary school judokas than in other age categories. Judo competition for Japanese elementary school judokas have been held at the regional level up to the national level. Meanwhile in France, national competitions for judokas under 13 years have not been implemented. The sample number of competitions for elementary school judokas in this study was too small to infer that competitions for the youngest athletes have higher risk of injury but does suggest increased major injury occurrence for young judokas who are still in early stages of physical and technique development.

With regard to weight category, major injury $\mathrm{IIR}_{\mathrm{AE}}$ was highest in middleweight category compared to others. Cierna et al. also reported middleweight as a significant risk factor of injury in epidemiological injury survey of elite European judo athletes in competition (10). Furthermore, the $\mathrm{IIR}_{\mathrm{AE}}$ of minor injury was higher in light and middleweight compared to heavy and open-weight categories in this study. This suggests that the incidence of minor injuries increases from grip fighting in light and middleweight class. There is no report investigating the relationship between weight difference between judoka and injury incidence. Although the weight differences between opponents for each bout were not verified in this study, our results suggested that the competition of open-weight category may not be a risk 
factor to injury because there was no difference of the $\mathrm{IIR}_{\mathrm{AE}}$ compared with other weight categories.

This study has several limitations. First, we were only able to verify injuries as reported by tatami healthcare professionals, thus, this invariably excludes some injuries (inadvertently) not reported during competition. Secondly, the time from injury to definitive diagnosis at a medical institution was not ascertained. Akoto et al. advocated the importance of time-loss injuries, which take over 3 weeks to return to competition (21). Similarly, Malliaropoulos et al. also indicated the importance of developing effective prevention programmes for sports related injury and recommended a warm up programme (Judo 9+) specialised for judo (12). In addition to these efforts to prevent injury, future establishment of a comprehensive training programme for tatami healthcare professionals is necessary for the safe management of Judo competitions. To develop effective prevention programmes to prevent judo injuries, meticulous recording of all judo injuries both at national and international levels and video analysis of these injuries are strongly recommended (25).

\section{REFERENCES}

1. International Judo Federation. Available from: https://en.wikipedia.org/wiki/International_Judo_Federation. Accessed 1 January 2019.

2. International Judo Federation. History-Timeline. Available from:

https://www.ijf.org/history/timeline. Accessed 1 January 2019.

3. Pocecco E, Ruedl G, Stankovic N, et al. Injuries in judo: a systematic literature review including suggestions for prevention. Br J Sports Med. 2013;47:1139-1143.

4. Junge A, Engebretsen L, Mountjoy ML, et al. Sports injuries during the summer Olympic games 2008. Am J Sports Med. 2009;37:2165-2172.

5. Engebretsen L, Soligard T, Steffen K, et al. Sports injuries and illnesses during the London summer Olympic games 2012. Br J Sports Med. 2013;47:407-414.

6. James G, Pietcr W. Injury rates in adult elite judoka. Biol Sport. 2003;20:25-32.

7. Green AM, Petrou MJ, Fogarty-Hover MLS, Rolf CG. Injuries among judokas during competition. Scand J Med Sci Sports. 2007;17:205-210.

8. Pieter W, De Crce C. Competition injuries in young and adult judo athletes. Proceedings of the 2nd Annual Congress of the European College of Sport Science; Aug 20-23; Copenhagen, Denmark; 1997.

9. Kim KS, Park KJ, Lee J, Kang BY. Injuries in national Olympic level judo athletes: an epidemiological study. Br J Sports Med. 2015;49:1144-1150.

10. Cierna D, Štefanovský M, Matejová L, Lystad RP. Epidemiology of competition injuries in elite European judo athletes: A prospective cohort study. Clin J Sport Med. 2017.
In conclusion, the present study provides the latest knowledge on the frequency and characteristics of injuries during judo competition and awareness for tatami healthcare professionals. Minor injuries occurred four times more often than major injuries. The most common minor injury was soft tissue injury (bleeding) and major injury was sprain. Injuries needing emergency transportation to medical institution occurred 1.5 per 1,000 athletes-exposures. Tatami health care professionals must be trained to offer adequate timely effective care for injuries commonly suffered by judokas during a competitive bout.

\section{CONFLICT OF INTERESTS}

The authors declare that they have no conflicts of interest.

\section{ACKNOWLEDGEMENTS}

We would like to thank All Japan Judo Federation Medical Committee's member for collecting the data. This study was not supported by any outside funding agency.

11. Yard EE, Knox CL, Smith GA, Comstock RD. Pediatric martial arts injuries presenting to Emergency Departments, United States 1990-2003. J Sci Med Sport. 2007;10:219-226.

12. Malliaropoulos NG, Callan M, Johnson J. Comprehensive training programme for judo players nine plus 9+: possible lower limb primary injury prevention. Muscles Ligaments Tendons. J. 2014;4:262-268.

13. Padulo J, Oliva F, Frizziero A, Maffulli N. Muscles, Ligaments and Tendons Journal - Basic principles and recommendations in clinical and field Science Research: 2016 Update. Muscles Ligaments Tendons J. 2016;6:1-5.

14. Miarka B, Bello FD, Brito CJ, et al. Injuries during a World Judo Championship: Differences between sex, weight category and competition phase. Int J Perform Anal Sport. 2018;18:229244.

15. Pierantozzi E, Muroni R. Judo high level competitions injuries. Medit J Musc Surv. 2009;17:26-29.

16. International Judo Federation. Injury, illness or accident, Article 20, Sports and Organisation Rules of the International Judo Federation, Lausanne, Switzerland, 2018.

17. Souza M, Monteiro H, Del Vecchio F, Gonçalves A. Referring to judo's sports injuries in Sao Paulo State Championship. Sci Sports. 2006;21:280-284.

18. Sterkowicz S, Rukasz W. Typowe urazowe uszkodzenia ciala I opolne wskazania w rehabilitacji ruchowej judokow. Medycyna Sportowa. 1996;64/65:12-17 (in Polish).

19. Kamitani T, Nimura Y, Nagahiro S, Miyazaki S, Tomatsu T. Catastrophic head and neck injuries in judo players in Japan from 2003 to 2010. Am J Sports Med. 2013;41:1915-1921. 
20. Nagahiro S, Mizobuchi Y. Current topics in sports-related head injuries: A Review. Neurol Med Chir (Tokyo). 2014;54:878886.

21. Akoto R, Lambert C, Balke M, Bouillon B, Frosch KH, Höher J. Epidemiology of injuries in judo: a cross-sectional survey of severe injuries based on time loss and reduction in sporting level. Br J Sports Med. 2018;52:1109-1115.

22. Fuller CW, Molloy MG, Bagate C, et al. Consensusu statement on injury definitions and data collection procedures for studies of injuries in rugby union. Br J Sports Med. 2007;41:328-331.
23. Gabbe BJ, Finch CF, Bennell KL, Wajswelner H. How valid is a self reported 12 month sports injury? Br J Sports Med. 2003;37:545-547.

24. Kujala UM, Taimela S, Antti-Poika I, Orava S, Tuominen R, Myllynen P. Acute injuries in soccer, ice hockey, volleyball, basketball, judo, and karate: analysis of national registry data. BMJ. 1995;311:1465-1468.

25. Kamitani T, Malliaropoulos NG, Omiya M, Otaka Y, Inoue K, Onidani N. On the way to the Tokyo Summer Olympic Games (2020). Prevention of severe head and neck injuries in judo: it's time for action. Br J Sports Med. 2017;51:1581-1582. 